presence of anti-cN-1A. Anti-cN-1A positivity had a sensitivity of $43.6 \%$ and a specificity of $91.8 \%$ for sIBM. The positive and negative predictive values were $36.4 \%$ and $93.8 \%$, respectively.

There was no significant difference in gender, age at study entry, age at symptom onset, duration of symptoms or max creatine kinase (CK) levels during disease course between the anti-cN-1A positive and negative slBM patients. Dysphagia was present in $19(79 \%)$ of the anti-cN-1A positive and in $17(55 \%)$ of the anti-cN-1A negative sIBM patients $(P=0.06)$.

Conclusion: Antibodies against $\mathrm{cN}-1 \mathrm{~A}$ are the first and so far the only serological marker for sIBM. Our data showed that $\mathrm{cN}-1 \mathrm{~A}$ autoantibodies are specific for sIBM and further corroborate the potential diagnostic role of $\mathrm{cN}-1 \mathrm{~A}$ autoantibodies in this distinct subgroup of myositis.

Disclosure of Interests: Louise Pyndt Diederichsen: None declared, Sine Søndergaard Korsholm: None declared, Line Vinderslev Iversen: None declared, Christoffer Tandrup Nielsen: None declared, Marie-Louise From Hermansen: None declared, Søren Jacobsen: None declared, Nanna Witting: None declared, Markus E. Krogager: None declared, Tina Friis Grant/research support from: Anti cN-1A ELISA kits and EUROLINE Autoimmune Inflammatory Myopathies 16 AG kits have been provided for a project free of charge from Euroimmun.

DOI: 10.1136/annrheumdis-2019-eular.7264

\section{FRI0321 PERFORMANCE OF DIFFERENT PULMONARY HYPERTENSION SCREENING ALGORITHMS IN PATIENTS WITH SYSTEMIC SCLEROSIS PATIENTS}

Mustafa Erdogan ${ }^{1}$, Burcak Kilickiran Avci $^{2}$, Yagmur Ersoy $^{3}$, Cansu Ebren $^{2}$ Zeki Ongen ${ }^{2}$, Gul Ongen ${ }^{4}$, Vedat Hamuryudan ${ }^{1}$, Gulen Hatemi ${ }^{1} .{ }^{1}$ Istanbul University -Cerrahpasa Medical Faculty, Internal Medicine, Division of Rheumatology, Istanbul, Turkey, ${ }^{2}$ Istanbul University -Cerrahpasa Medical Faculty, Department of Cardiology, Istanbul, Turkey, ${ }^{3}$ Istanbul University -Cerrahpasa Medical Faculty, Istanbul, Turkey; ${ }^{4}$ Istanbul University -Cerrahpasa Medical Faculty, Department of Pulmonary Diseases, Istanbul, Turkey

Background: Pulmonary hypertension $(\mathrm{PH})$ is an important cause of morbidity and mortality in patients with systemic sclerosis (SSc). Different screening algorithms have been proposed for identifying patients who have a high probability of $\mathrm{PH}$ and require right heart catheterization $(\mathrm{RHC})$, which is the gold standard for diagnosing $\mathrm{PH}$.

Objectives: To compare the performance of $\mathrm{PH}$ screening algorithms in our patients with SSc.

Methods: Forty-eight consecutive patients, fulfilling ACR/EULAR 2013 SSC criteria, were screened for PH using the, 2015 ESC/ERS, DETECT and ASIG algorithms. Pulmonary function tests (PFT), diffusing capacity of the lung for carbon monoxide (DLCO), trans-thoracic echocardiography, serum NT-proBNP, uric acid assay and high-resolution computed tomography (HRCT) were performed as needed. Patients with known $\mathrm{PH}$, severe interstitial lung disease and severe left ventricular dysfunction were not included. $\mathrm{RHC}$ was performed in all patients with positive screening according to any one of the screening algorithms. Patients with $\mathrm{PH}$ were classified according to the updated $\mathrm{PH}$ classification criteria. Sensitivity and specificity of the 3 screening algorithms were evaluated according to the established cut-off value of $25 \mathrm{mmHg}$ for mean systolic pulmonary artery pressure and for the recently proposed cut-off value of $20 \mathrm{mmHg}$ Results: Among the 48 SSc patients, 15 were excluded due to already diagnosed $\mathrm{PH}(n=4)$, left ventricular dysfunction $(n=4)$, no measurable tricuspid regurgitation velocity (TRV) $(n=5)$ and coexisting lung cancer $(n=2)$. Among the remaining 34 patients, 16 required $\mathrm{RHC}$ according to at least one of the screening algorithms. Demographic and clinical features of remaining 34 patients were summarized in Table 1. Number of patients who had suspected pulmonary hypertension and required $\mathrm{RHC}$ according to ESC/ERS 2015, DETECT and ASIG were 8 (\%25), 9 (\% $27)$, and $13(\% 41)$ respectively (Figure 1). Among the 14 who had RHC, $\mathrm{PH}$ was present in 3 patients according to the 25-mmHg cut-off (Group1 in 1, Group 2 in 1, Group 3 in 1) and in 8 patients according to the 20-mmHg cut-off (Group 1 in 5, Group 2 in 2, Group 3 in 1). The sensitivity and specificity of each algorithm is presented in Table 2. Sensitivity was similar at $100 \%$ for the 3 algorithms, but the ESC/ERS algorithm had better specificity, when $\mathrm{PH}$ was diagnosed with the $25-\mathrm{mmHg}$ cut-off. For the $20-\mathrm{mmHg}$ cut-off, both the sensitivity and the specificity were better with the ESC/ERS algorithm.

Conclusion: The ESC/ERS algorithm seems to have a better performance for detecting $\mathrm{PH}$ in patients with SSc. A limitation of this study was that $\mathrm{RHC}$ was not performed in patients who did not fulfill criteria according to any of the screening algorithms. The sensitivities may be lower than what we propose if there are patients with $\mathrm{PH}$ who are asymptomatic and not captured with any of the algorithms.

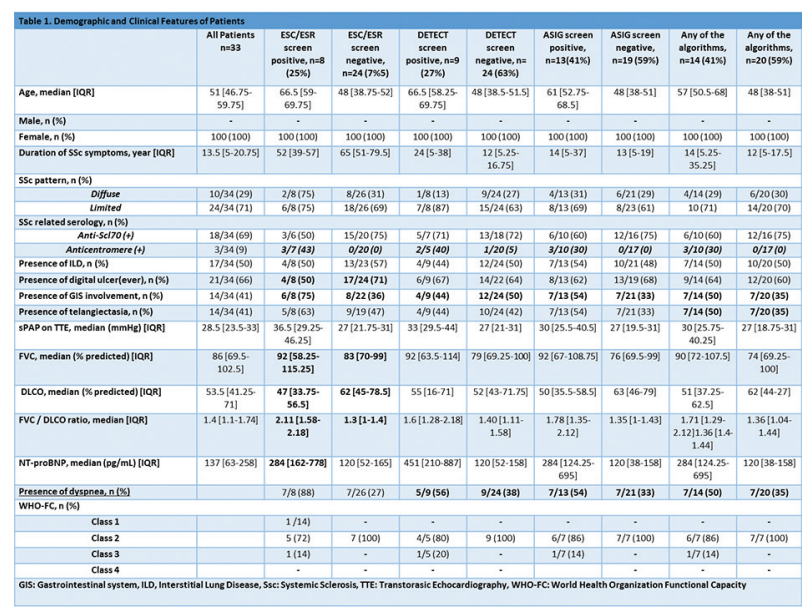

Disclosure of Interests: Mustafa Erdogan: None declared, Burcak Kilickiran Avci: None declared, Yagmur Ersoy: None declared, Cansu Ebren: None declared, Zeki Ongen: None declared, Gul Ongen: None declared Vedat Hamuryudan Consultant for: Abbvie, Amgen, BMS, Jansen, MSD, Pfizer, UCB, Speakers bureau: Abbvie, Amgen, BMS, Jansen, MSD Pfizer, UCB, Gulen Hatemi Consultant for: Abbvie, Amgen, BMS, Janssen, MSD, Pfizer, UCB, Speakers bureau: Abbvie, Amgen, BMS, Jansen MSD, Pfizer, UCB,

DOI: 10.1136/annrheumdis-2019-eular.2662

\section{FRI0322 AUTOANTIBODIES PROFILE INFLUENCE ON SYSTEMIC SCLEROSIS INTERSTITIAL LUNG DISEASE. A TERTIARY SPANISH HOSPITAL EXPERIENCE}

Antía García Fernández ${ }^{1}$, Iván del Bosque Granero ${ }^{1}$, Laura Calvo Sanz ${ }^{1}$, Nicolás Almeida Arostegui ${ }^{2}$, Luis Gorospe Sarasúa ${ }^{2}$, Carlos De la Puente Bujidos ${ }^{1}$

${ }^{1}$ Ramón y Cajal University Hospital, Rheumatology, Madrid, Spain; ${ }^{2}$ Ramón y Cajal University Hospital, Radiology, Madrid, Spain

Background: Systemic Sclerosis (SSc) is a rare and heterogeneous connective tissue disease (CTD) characterized by skin fibrosis, vasculopathy/vascular damage and potential visceral impairment. Interstitial lung disease (ILD) constitutes the leading cause of mortality and requires close periodical assessment and follow-up. Diffuse cutaneous sclerosis and specific autoantibody profile (anti SCL70 anti Th/To, Anti U3 RNP and anti PmScl) are considered ILD development risk factors. In contrast, positivity to anticentromere has been considered as a protec tive factor to develop a clinical significant ILD.

Objectives: To assess ILD frequency and severity (extension and func tional impairment) in SSc patients, analyzing the association with the different autoantibodies.

Methods: Retrospective, descriptive study of patients meeting EULAR/ACR 2013 SSc criteria and had a HRTC performed at a tertiary Spanish hospital from 1975 to 2018. One hundred and eight patients were included HRCTs were graded by two radiologists according to Goh et al semiquantitative score. Three groups were established according to the pres ence of different autoantibodies: anticentromere (ACA), antitopoisomerase (ATA), and positivity to other ANAs (nucleolar pattern and other specificities).

Results: Clinical and laboratory characteristics are presented in table 1 . Thirty-three patients had pulmonary involvement, 6 were ACA+, 18 ATA+ and 9 had other ANA specificities. The probability of not having pulmonary involvement among $\mathrm{ACA}+$ and of having pulmonary involvement among ATA + showed statistic significance $(p<0.001$ and $p<0.001)$. Usual intestinal Pneumonia (UIP) was the most frequently reported pattern (6 patients), followed by Non-Specific Interstitial Pneumonia (NSIP 11 patients); Six patients did not meet the radiological criteria for neither UIP or NSIP. No statistical significant difference was found among radio logical pattern and autoantibody profile. Regarding extension: 15 patients 